\title{
Methylsulfonylmethane inhibits HER2 expression through STAT5b in breast cancer cells
}

\author{
DONG YOUNG KANG ${ }^{1}$, PRAMOD DARVIN ${ }^{1}$, YOUNG BEOM YOO ${ }^{2}$, YOUN HEE JOUNG ${ }^{1}$, \\ NIPIN SP ${ }^{1}$, HYO JOO BYUN ${ }^{1}$ and YOUNG MOK YANG ${ }^{1}$ \\ ${ }^{1}$ Department of Pathology, School of Medicine, and Institute of Biomedical Science and Technology, \\ ${ }^{2}$ Department of Surgery, School of Medicine, Konkuk University, Seoul, Republic of Korea
}

Received October 16, 2015; Accepted November 22, 2015

DOI: $10.3892 /$ ijo.2015.3277

\begin{abstract}
Breast cancer is the most common cancer in women globally. The factors that increase risk include: late age at first birth, alcohol, radiation exposure, family history of breast cancer, and postmenopausal hormone therapy. Numerous drugs are being developed to treat breast cancer. Among them, Herceptin is used for the treatment of human epidermal growth factor receptor 2 (HER2)-positive cases and targets HER2 effectively and efficiently, but it is very expensive. Methylsulfonylmethane (MSM) is an organic sulfur-containing natural compound having no reported toxicity. We examined MSM in breast cancer cell lines and found it inhibited the proliferation of estrogen receptor-positive and HER2-positive breast cancer cells in a dose-dependent manner. It also suppressed the activation of STAT5b and expression of HER 2 in breast cancer cells. We determined the STAT5b binding site (GAS element) in the HER2 gene. Detailed analysis showed that MSM decreased the ability of STAT5b to bind the promoter of the HER2 gene and a luciferase assay demonstrated reduced activity. We confirmed that MSM can effectively regulate STAT5b, and thereby decrease HER2 expression. Therefore, we recommend the use of MSM as an inhibitor for the management of HER2-positive breast cancers.
\end{abstract}

\section{Introduction}

Breast cancer is one of the most commonly diagnosed cancers and the leading cause of cancer-related death in females worldwide (1). The factors that increase risk include: late age of first birth, alcohol consumption, and postmenopausal hormone therapy or oral contraceptives (2-4). Breast cancer

Correspondence to: Professor Young Mok Yang, Department of Pathology, School of Medicine, and Institute of Biomedical Science and Technology, Konkuk University, Seoul 143-701, Republic of Korea

E-mail: ymyang@kku.ac.kr

Key words: breast cancer, methylsulfonylmethane, HER2, STAT5b, SK-BR3 can be classified into different molecular subtypes based on the hormone responsive surface receptors (5). Luminal A [estrogen receptor $(\mathrm{ER})^{+}$, progesterone receptor $(\mathrm{PR})^{+/-}$, human epidermal growth factor receptor 2 (HER2)]', luminal B $\left(\mathrm{ER}^{+}, \mathrm{PR}^{+-}, \mathrm{HER} 2^{+}\right), \mathrm{HER} 2\left(\mathrm{ER}^{-}, \mathrm{PR}^{-}, \mathrm{HER} 2^{+}\right)$, and basal (ER', PR-, HER2-). Luminal A tumors tend to have a good prognosis, with high survival rates and fairly low recurrence rates $(6,7)$; in addition, $\leq 15 \%$ of luminal A tumors have p53 mutations. Luminal B tumors are larger, HER2-positive, and $\leq 30 \%$ have p53 mutations. Luminal A tumors grow very slowly compared with luminal B tumors (8). Basal tumors (triple-negative breast cancers - TNBC) represent $\sim 20 \%$ of breast cancers (8-10) and they tend to occur in younger women and in African American women $(8,11)$. Approximately $20 \%$ of breast cancers are HER2-positive due to over-production of the HER2 protein. This type tends to be aggressive and fast-growing (12-15) and $\leq 75 \%$ of cases have p53 mutations; in addition, this type has a poor prognosis and is prone to frequent recurrence and metastasis $(6,8)$.

There are four different types of HER receptors (HER1, HER2, HER3, HER4) (16). The HER gene is located on chromosome 17. Activation of the HER2/neu oncogene leads to the production of HER2 (17). Overexpression of the HER2/neu gene is associated with breast, ovarian, and several other types of cancer with high transition probability (18). The binding of specific ligands leads to the activation of the tyrosine kinase activity of HER2 and cell survival, which in turn leads to the uncontrolled growth of cancer cells. The STAT proteins are expressed in all types of breast cancer cells and tissues (19) and have pivotal roles in apoptosis, differentiation, and proliferation (20). The Jak/STAT pathways are activated by various factors and cytokines, leading to the activation of Jak tyrosine kinase followed by tyrosine phosphorylation of the receptors. The role of the HER2 and STAT3 signaling network has been confirmed in breast cancer cells (21), and HER 2 expression can be modulated through the STATs.

Methylsulfonylmethane (MSM) is a simple organic sulfur-containing compound and a stable, odorless, colorless, non-toxic, crystalline product (22). MSM is found in foods, including fruits, vegetables, and grains (23-25). It is known for its effects on allergies, skin diseases, and arthritis $(26,27)$. In addition to these medicinal properties, MSM showed growth promoting activities by enhancing the differentiation of 
mesenchymal stem cells (28). In addition, MSM suppressed tumor growth and progression $(29,30)$. We reported that MSM suppresses breast cancer growth through modulating STAT3 and STAT5b pathways (29). In addition, MSM is active against HER2-positive breast cancers; although, the molecular mechanism behind this activity is unclear. The expression levels of HER2 are associated with a number of factors. In the present study, we examined MSM in breast cancer cell lines and hypothesized that this compound inhibits HER2 gene expression through STAT5b in SK-BR3 cells.

\section{Materials and methods}

Antibodies and reagents. The following were purchased from the indicated sources: penicillin-streptomycin solution and fetal bovine serum (FBS) from Hyclone (South Logan, UT, USA); RPMI-1640 from Sigma Chemical Co. (St. Louis, MO, USA); trypsin-EDTA (0.05\%) from Gibco-BRL (Grand Island, NY, USA); STAT5b, HER2 antibodies, and secondary antibody (goat anti-mouse and rabbit IgG-horseradish peroxidase) from Santa Cruz Biotechnology (Santa Cruz, CA, USA); phosphorylated STAT5 from Upstate Biotechnology (Lake Placid, NY, USA); $\beta$-actin from Sigma Chemical Co.; the enhanced chemiluminescence (ECL) detection kit from Amersham Pharmacia Biotech (Piscataway, NJ, USA); Restore ${ }^{\mathrm{TM}}$ Western Blot Stripping Buffer and NE-PER kit from Pierce (Rockford, IL, USA); the electrophoretic mobility shift assay (EMSA) kit, oligonucleotide probes (STAT5b), luciferase assay substrates, and reporter lysis buffer from Promega Corp. (Madison, WI, USA); FuGENE6 transfection reagent from Roche (Basel, Switzerland); RNeasy mini kit and Qiaprep spin miniprep kit from Qiagen (Hilden, Germany); the RT-PCR Premix kit and VEGF, IGF-1R, 18s primer for RT-PCR were synthesized by Bioneer (Dajeon, Korea); imprint chromatin immunoprecipitation assay kit from Sigma Chemical Co.; and MSM from Fluka/Sigma Co. (St. Louis, MO, USA).

Cell culture and treatment. The human breast adenocarcinoma cell lines, SK-BR3 and MCF-7, were maintained in RPMI-1640 medium containing $10 \% \mathrm{FBS}$ and $100 \mathrm{U} / \mathrm{ml}$ penicillin and streptomycin at $37^{\circ} \mathrm{C}$ in $5 \% \mathrm{CO}_{2}$. The cells were placed in airtight chambers ( $\mathrm{Nu}$ Aire, Plymouth, MN, USA). At the beginning of each experiment, the cells were resuspended in the medium at a density of $2.5 \times 10^{5}$ cells $/ \mathrm{ml}$. Cells were treated with $300 \mathrm{mM}$ MSM.

Cell proliferation inhibition. Cell viability was assayed by measuring blue formazan that was metabolized from 3-(4,5-dimethylthiazol-2-yl)-2,5-diphenyl tetrazolium bromide (MTT) by mitochondrial dehydrogenase, which is only active in live cells. The cells were resuspended in the medium one day before drug treatment, at a density of $3 \times 10^{3}$ cells per well in 96-well culture plates. Liquid medium was replaced with fresh medium containing dimethyl sulfoxide (DMSO) as a control (vehicle). Cells were incubated with various concentrations of MSM. Then, MTT $(5 \mathrm{mg} / \mathrm{ml})$ was added to each well and incubated for $4 \mathrm{~h}$ at $37^{\circ} \mathrm{C}$. The formazan product formed was dissolved by adding $200 \mu \mathrm{l}$ DMSO to each well, and the absorbance was measured at $550 \mathrm{~nm}$ on an Ultra Multifunctional Microplate Reader (Tecan, Durham, NC, USA). All measure- ments were performed in triplicate, and were repeated at least three times.

Western blotting. The SK-BR3 and MCF-7 cell lines were treated with MSM. Whole cells were lysed on ice with radioimmunoprecipitation (RIPA) lysis buffer, containing phosphatase and protease inhibitors. Cells were disrupted by aspiration through a 23 -gauge needle, and centrifuged at $15,000 \mathrm{rpm}$ for $10 \mathrm{~min}$ at $4^{\circ} \mathrm{C}$ to remove cellular debris. Protein concentrations were measured using the Bradford method. Equal amounts of proteins were resolved with sodium dodecyl sulfate-polyacrylamide gel electrophoresis (SDS-PAGE) and transferred onto nitrocellulose membranes. The blots were blocked for $1 \mathrm{~h}$ with $5 \%$ skim milk. Membranes were probed overnight at $4{ }^{\circ} \mathrm{C}$ with a primary antibody followed by horseradish peroxidaseconjugated secondary antibodies. Detection was performed using the ECL Plus detection kit and a LAS-4000 imaging device (Fujifilm, Japan).

Reverse transcription polymerase chain reaction (RT-PCR). Total RNA was extracted using the RNeasy Mini kit (Qiagen) and quantified spectrometrically at $260 \mathrm{~nm}$. Then, RT-PCR analysis for HER2 and 18s RNA was performed. The cDNA was synthesized from total RNA by RT at $42^{\circ} \mathrm{C}$ for $1 \mathrm{~h}$ and $95^{\circ} \mathrm{C}$ for 5 min using first strand cDNA synthesis kits (Bioneer, Korea). The cDNA was used in PCR with the following primers: HER2 sense, 5'-TGCGGCTCGTACACAGGGACTT-3' and HER2 antisense, 5'-TGCGGAGAATTCAGACACCAACT-3', with a 420-bp amplified HER2 mRNA fragment; 18s sense, 5'-CGGCTACCACATCCAAGGAA-3' and 18s antisense, 5'-CCGGCGTCCCTCTTAATC-3', with a 489-bp amplified 18s mRNA fragment. The PCR conditions consisted of denaturation for $1 \mathrm{~min}$ at $95^{\circ} \mathrm{C}$, annealing for $1 \mathrm{~min}$ at $58^{\circ} \mathrm{C}$, and extension for $1 \mathrm{~min}$ at $72^{\circ} \mathrm{C}$. The PCR products were analyzed on a $1 \%$ agarose gel stained with ethidium bromide.

Electrophoretic mobility shift assay (EMSA). The DNA binding activity of STAT5b was assessed using EMSA, in which labeled double-stranded DNA was used as a DNA probe to bind active STAT5b proteins in nuclear extracts. Nuclear protein extracts were prepared with a nuclear extract kit (Panomics, AY2002). The EMSA experiment was performed by incubating a biotin-labeled transcription factor-STAT5b probe with treated and untreated nuclear extracts. Proteins were resolved on a non-denaturing $6 \%$ polyacrylamide gel (Bio-Rad, Korea). The proteins in the gel were transferred to a nylon membrane and detected using streptavidin-horseradish peroxidase and a chemiluminescent substrate.

Chromatin immunoprecipitation (ChIP) assay. The ChIP assay was performed using the Imprint chromatin immunoprecipitation kit (Sigma) according to the manufacturer's protocol. Briefly, SK-BR3 cells were fixed with $1 \%$ formaldehyde and quenched with 1.25 M glycine. After washing with PBS, the cells were suspended in nuclei preparation buffer and shearing buffer and sonicated under optimized conditions. This sheared DNA was then centrifuged and the cleared supernatant used for protein/DNA immunoprecipitation. The clarified supernatant was diluted with buffer (1:1 ratio) and $5 \mu 1$ of the diluted samples was removed as an internal control. The diluted supernatant 


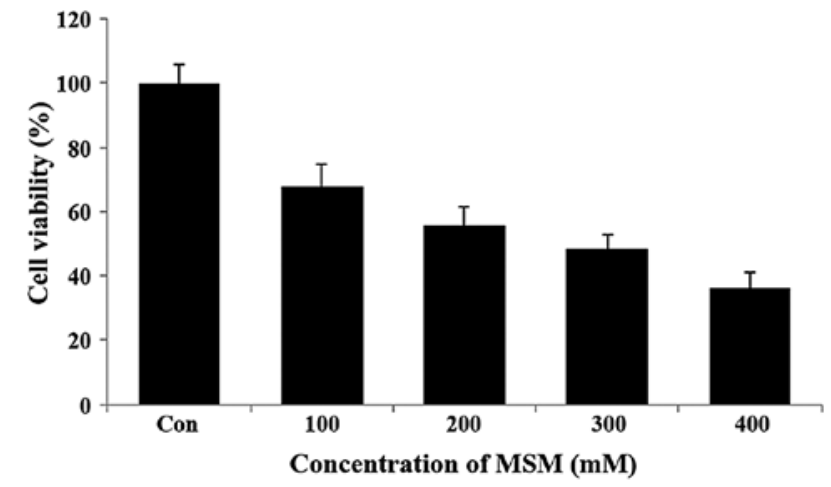

Figure 1. Effects of MSM on viability in SK-BR3 cells. Evaluation of cell viability of SK-BR3 using MTT assay. Cell growth was inhibited $\sim 51 \%$ at a concentration of $300 \mathrm{mM}$ MSM for $24 \mathrm{~h}$, which is used as $\mathrm{IC}_{50}$ dosage.

was incubated with antibody (STAT5b) in pre-coated wells for $90 \mathrm{~min}$. The negative and positive controls were normal goat IgG and anti-RNA polymerase II, respectively. The unbound DNA was washed off with IP wash buffer and the bound DNA was collected by cross link reversal using DNA release buffer containing proteinase $\mathrm{K}$. The released DNA and DNA from the internal control were purified with the GenElute Binding Column G. The DNA was then quantified using conventional PCR.

Expression vectors, transfection, and the luciferase reporter assay. Cells were co-transfected with various combinations of the following constructs: wild-STAT5b (pMX/STAT5b; kindly provided by Dr Koichi Ikuta, Kyoto University, Japan), constructed as previously described (38), and the HER2 reporter construct containing $5.6 \mathrm{~kb}$ of the HER2 promoter region. Transfected cells were washed with ice-cold PBS and lysed. Lysates were used directly to measure luciferase activity. The luciferase activity of each sample was determined by measuring luminescence for $10 \mathrm{sec}$ on a Lumat LB 9507 luminometer (EG\&G Berthold, TN, USA). The experiments were performed in triplicate, and similar results were obtained from at least three independent experiments.

Small interference RNA (siRNA) analysis. SK-BR3 cells $\left(1 \times 10^{5}\right)$ were cultured on 6 -well plates and grown to $50 \%$ confluence. The cells were then transfected with On-Target plus SMARTpool siRNA targeting STAT5b or On-Target plus non-targeting siRNA (Dharmacon, Chicago, IL, USA) using FuGENE6 (Roche, IN, USA), according to the manufacturer's instructions. Following transfection with this mixture for $48 \mathrm{~h}$, invasion assays were conducted without adding drugs for an additional $24 \mathrm{~h}$. Different areas were captured and the cells were counted.

\section{Results}

MSM inhibits SK-BR3 cell proliferation. The effect of MSM on the viability of the human breast cancer cell line SK-BR3 was examined using the MTT assay. The SK-BR3 cells were exposed to increasing concentrations of MSM (100, 200, 300 and $400 \mathrm{mM}$ ) for a period of $24 \mathrm{~h}$. Following this, the metabolically viable cells were quantified based on the amount of formazan crystals formed. Treatment with MSM substantially decreased the viability of SK-BR3 cells in a dose-dependent manner. It was observed that $100 \mathrm{mM}$ MSM inhibited SK-BR3 cell growth by $32 \%, 200 \mathrm{mM}$ MSM by $45 \%$, and $300 \mathrm{mM}$ MSM by $51 \%$ (Fig. 1). Therefore, the $300-\mathrm{mM}$ concentration of MSM is considered the $\mathrm{IC}_{50}$ dosage and was used in the further experiments.

MSM suppressed the expression, as well as phosphorylation, of STAT5b and HER2 in breast cancer cells. To study the effect of MSM on STAT5b and HER2, SK-BR3 and MCF-7 cells were treated with $300 \mathrm{mM}$ MSM for $24 \mathrm{~h}$. Whole cell lysates were prepared in 1X RIPA lysis buffer containing $1 \mathrm{X}$ protease and $1 \mathrm{X}$ phosphatase inhibitor. Western blotting of the whole cell lysates prepared from MSM-treated and non-treated cells showed a decrease in the expression and phosphorylation of STAT5 in MSM-treated cells. Concurrently, the expression of HER 2 also decreased in both SK-BR3 and MCF-7 cells (Fig. 2A). Compared with the control group, the MSM-treated group showed a $30 \%$ decrease in STAT5 phosphorylation (Fig. 2B); while, STAT5b and HER2 expression levels were inhibited $\sim 50$ and $40 \%$, respectively (Fig. 2B).

MSM suppresses the transcription activation functions of $S T A T 5 b$. We analyzed the expression of the STAT5b target gene, HER2. The RT-PCR analysis showed a decrease in the transcription of HER2 mRNA in MSM-treated cells (Fig. 2C) when amplifying HER2 with gene-specific primers and using 18 S RNA as a loading control. Treated cells had $\sim 25$ and $40 \%$ inhibition of HER 2 expression when compared with non-treated control SK-BR3 and MCF-7 cells, respectively (Fig. 2D). The ability of MSM to suppress HER2 expression was confirmed at the translational level.

MSM inhibits the binding of STAT5b to the HER2 gene promoter. A previous study showed STAT5 was a transcription factor for HER2. We then analyzed the nuclear level expressions of STAT5b and HER2 after MSM treatment. The nuclear extracts of the MSM-treated groups showed decreased levels of p-STAT5 and HER2 (Fig. 3A). Results from the electrophoretic mobility shift assay indicated that MSM suppressed the STAT5b-DNA binding activity in SK-BR3 cells (Fig. 3B). Therefore, it was necessary to determine the DNA-binding site of STAT5b, which we found corresponds to the interaction of STAT5b with the GAS element (TTCagcGAA) of the HER2 gene (Fig. 3C). There results proved that MSM inhibited the binding of p-STAT5 to the HER2 gene promoter site.

The DNA binding of STAT5b is inhibited by MSM. To perform transcriptional functions, phosphorylated STAT5b should translocate to the nucleus from the cytosol. Thus, these nuclear translocations were analyzed using the ChIP assay. We found that MSM treatment led to a decrease in the STAT5b binding to the HER2 promoter in SK-BR3 cells. The quantitative analysis by qPCR showed that MSM treatment inhibited binding of STAT5b to the HER2 promoter region in SK-BR3 cells (Fig. 3D). There was significant downregulation of DNA binding of STAT5b in MSM-treated cells. These results indicate MSM plays an important role in the suppression of binding. 
A

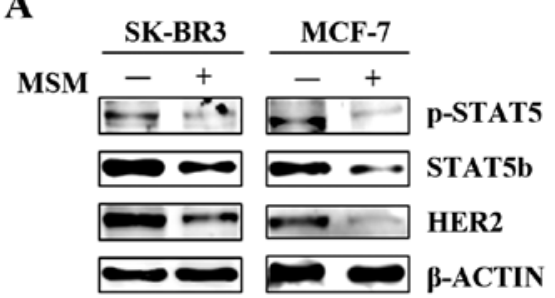

C

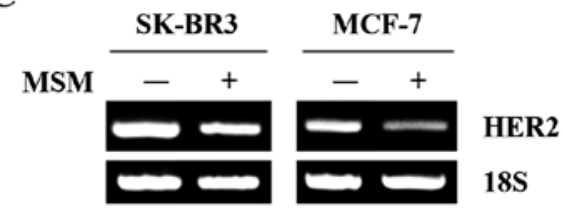

D

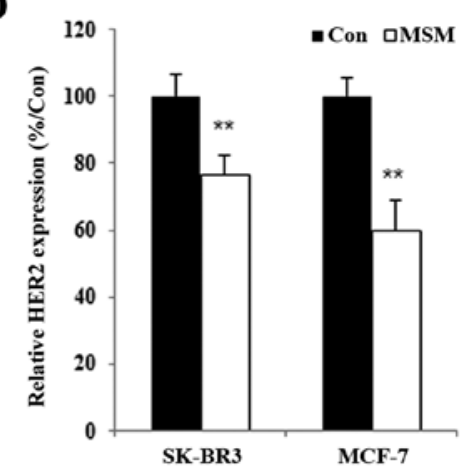

Figure 2. MSM suppresses STAT5b and HER2 expression activation in breast cancer cells. (A) Western blot analysis of cytoplasmic protein levels in SK-BR3 and MCF-7 cells after treatment with $300 \mathrm{mM}$ MSM for $24 \mathrm{~h}$. (B) The relative levels of p-STAT5, STAT5b and HER2 protein were determined using densitometric analysis and normalized to actin. Statistical analyses were conducted using the t-test $\left({ }^{* * *} \mathrm{P}<0.01,{ }^{* * * *} \mathrm{P}<0.001\right)$. (C) RT-PCR analysis of RNA levels of HER2 after the treatment with $300 \mathrm{mM}$ MSM in SK-BR3 and MCF-7 cells for $24 \mathrm{~h}$. (D) Relative expression levels of HER2 mRNA were determined using densitometric analysis and normalized 18S. Statistical analyses were conducted using the t-test $\left.{ }^{* * *} \mathrm{P}<0.01\right)$.

A

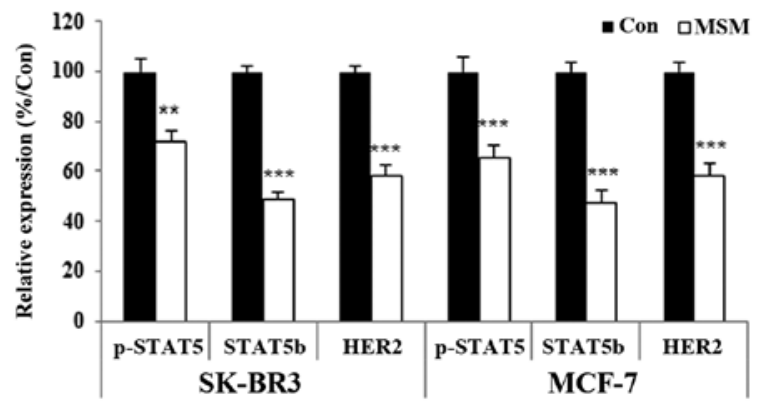

B

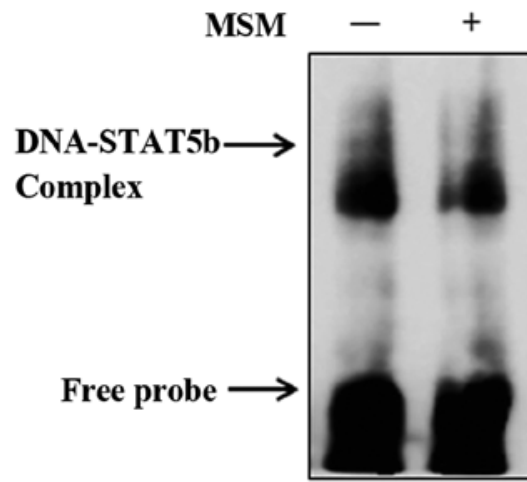

C

4201 ttggttctt gcceactatg gtccaateg aatgtaccag tccaagtcc ctcctcaaa 4261 caaaacgttc caagatgatc cctgecceca cgtettcasa gecggaactg acaccttcct 4321 atcecaatg cttcctaatc aagagtett tcaggggctc aascattct ctgecttgca 4381 cttgaaagg ctcatgtcec egtggggact gtgagtecca atgggcggga cectggtetg 4441 attergtge cattectaga eattgtggec cgaatgtatt taataaatac ectetgact 4501 gaacasataa gtaastgaa gctetctggga dagtaagaga ggctggtaag gctctcatca 4561 ccttagggge ttcactcaca ttcataagag acctegtggg gaaactaagg ttcagggatt 4621 gcagaggegt attgggggcg cagggggegg gagcaagaca aatgggeggg gcttaccgt 4681 ggggtggggc ttacctgcta gactcatgta gattggctgg cgggagcgga agtgattcag 4741 agcgecceca gageagtect gctctegca ctgeagtacg cagtegeggt acaceggetc 4801 acggtegece tgggagecge tegecagege cgetgececa getageagga ceaacegege 4861 egecaggecg gecatcett etcectgget cgecgecggg ggaggagett aggagtatga 4921 agcttccact tccggagtaa ecggaagte ctgtgttct tattctactc tecgetgaag 4981 tccacacagt traattaaqugttcceggat ttttgtgggc gectgececg cecctegtcc 5041 ecctgetgtg tccatatate gaggegatag ggttaaggga aggeggacge ctgatgggtt 5101 aatgagcaa ctgasgtgte ttccatgate tttttgagg tagggetgtt tactgtcace

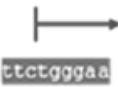

\section{: TSS (Transcription start site)}

GAS element (STAT5b binding sequences)
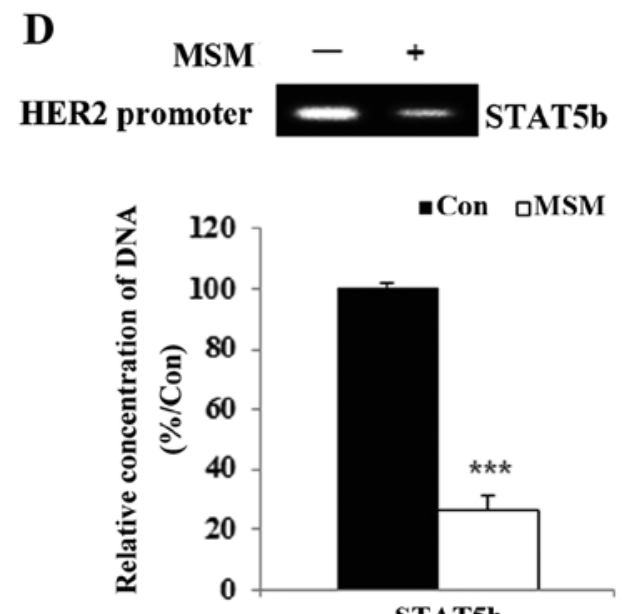

STAT5b

Figure 3. MSM inhibits the nuclear protein expression and the DNA binding activity of STAT5b. (A) Nuclear protein level analysis after treatment with $300 \mathrm{mM}$ MSM for $24 \mathrm{~h}$ by using western blotting. TBP was used as a control. (B) The DNA binding activity of STAT5b was inhibited by MSM, analyzed by gel shift assay. (C) Sequence of the human HER2 gene promoter (NCBI GenBank NG_007503.1//www.ncbi.nlm.nih.gov/nuccore/171906587). GAS element of HER2 gene is highlighted, and is present at nucleotide sequence 4523-4531. (D) ChIP analysis of levels of STAT5b-HER2 gene binding expression after the treatment with MSM $300 \mathrm{mM}$ in SK-BR3 cells for $24 \mathrm{~h}$ and quantified using real-time PCR. The relative DNA binding of STAT5b-HER2 gene were expressed as the percentage of control. Data shown are representative of three independent experiments. Asterisks indicate a significant increase by $\mathrm{t}-$ test $\left({ }^{* * * *} \mathrm{P}<0.001\right)$. 
B

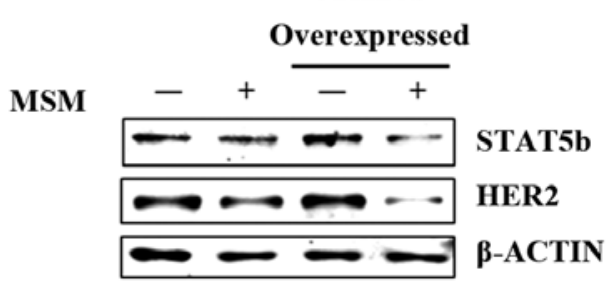

A

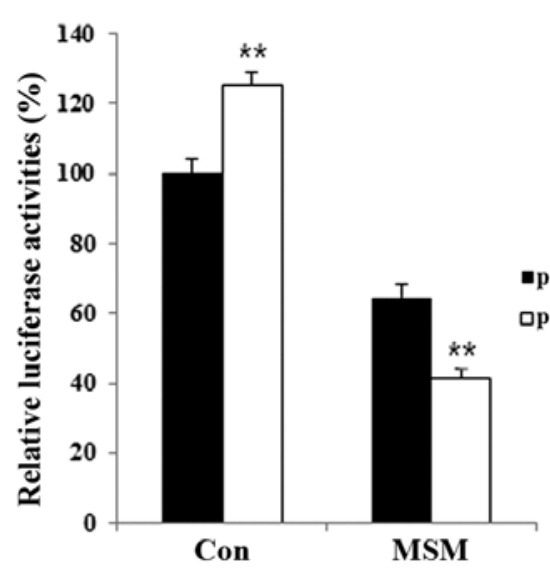

-pGL2/HER2

OpGL2/HER2/STAT5b C

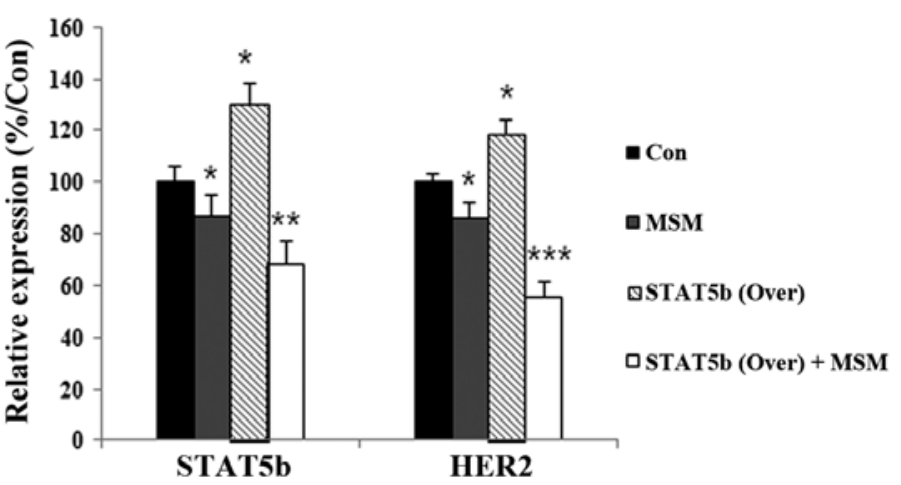

Figure 4. MSM inhibits the promoter functions of HER2. (A) MSM suppressed the promoter activity of HER2. SK-BR3 cells were transiently co-transfected with STAT5b and HER2 genes. Data represent means of at least three separate experiments. Asterisks indicate a significant decrease by $t$-test $\left.{ }^{* * * *} \mathrm{P}<0.001\right)$ in cross talk of STAT5b/HER2, respectively. (B) STAT5b overexpressing MCF-7 cells have been shown to decreased STAT5b and HER2 protein levels by treatment with $300 \mathrm{mM}$ MSM. (C) The relative levels of STAT5b and HER2 protein were determined using densitometric analysis and normalized to the amount of $\beta$-actin. Statistical analyses were conducted using the ANOVA test $\left({ }^{*} \mathrm{P}<0.05,{ }^{* * *} \mathrm{P}<0.01,{ }^{* * * *} \mathrm{P}<0.001\right)$. Data shown are representative of three independent experiments.
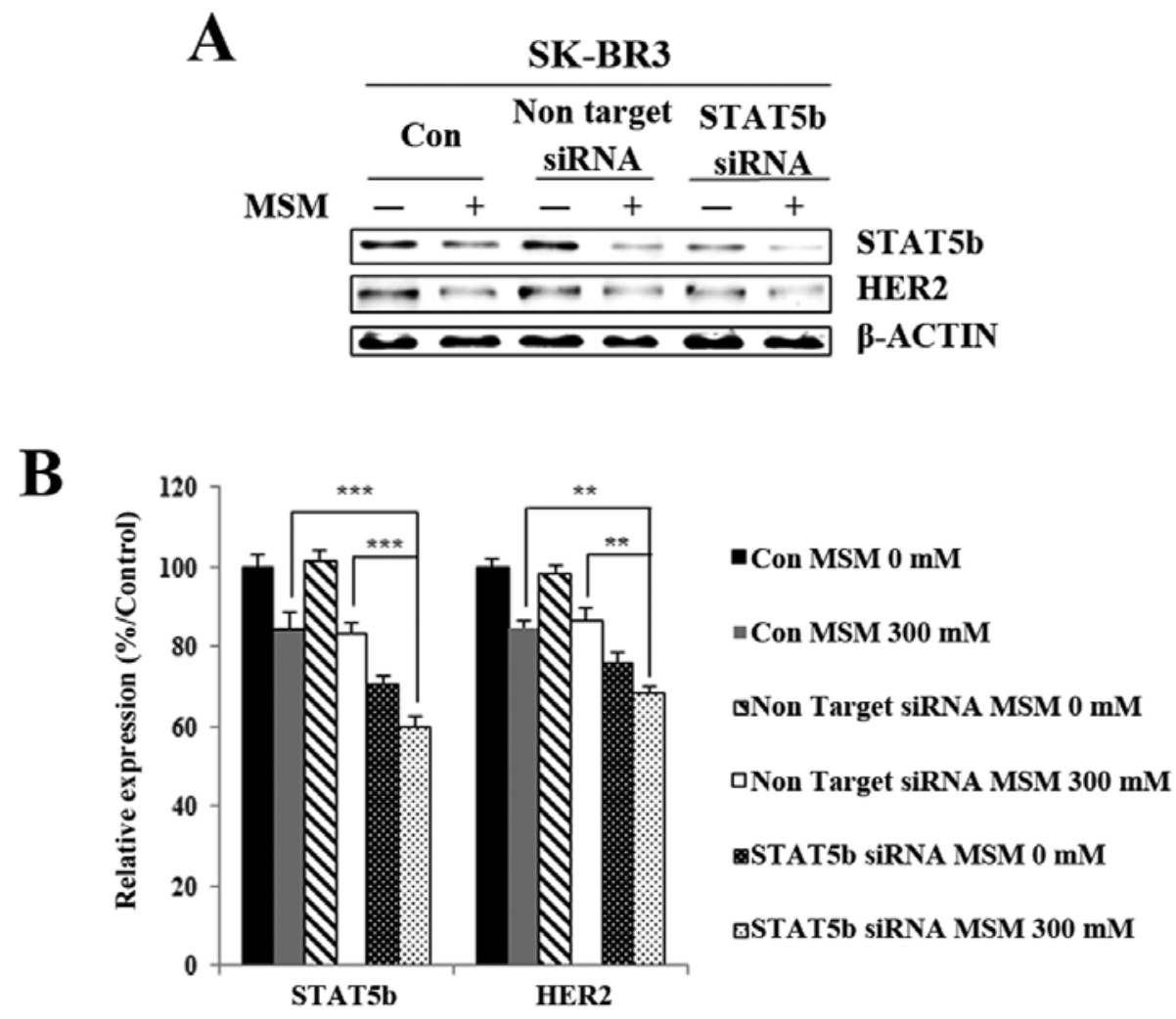

Figure 5. STAT5b regulates HER2 expression in SK-BR3 cells upon MSM treatment. (A) On-target inhibition of STAT5b decreased the expression pattern of HER2 after silenced STAT5b in SK-BR3 cells. (B) The relative levels of STAT5b and HER2 protein were determined using densitometric analysis and normalized to the amount of $\beta$-actin. Data shown are representative of three independent experiments. Asterisks indicate a significant increase by $t$-test $\left({ }^{* * *} \mathrm{P}<0.01,{ }^{* * * *} \mathrm{P}<0.001\right)$. 
MSM suppresses transcriptional activity between STAT5b and HER2 genes in SK-BR3 cells. The transcription activation functions of STAT5b after MSM treatment were studied using a luciferase assay. After treatment with MSM for $24 \mathrm{~h}$, relative luciferase activity was decreased significantly for STAT5b/HER2 (Fig. 4A, ${ }^{* * *} \mathrm{P}<0.001$ ). This finding confirms the critical role of MSM in inhibiting the transcription promoter activities of STAT5b.

MSM inhibits STAT5b and HER2 expression at the translational and transcriptional levels. To analyze the correlation between STAT5b and HER2, we overexpressed the STAT5b protein in MCF-7 cells. After transfection with STAT5b for overexpression, we analyzed the expression of STAT5b and HER2 using western blotting (Fig. 4B). Treatment with MSM led to $\sim 15 \%$ inhibition of STAT5b and HER2 compared with the control in MCF-7 cells. In cells overexpressing STAT5b, the MSM treatment led to $\sim 60 \%$ inhibition of STAT $5 \mathrm{~b}$ and HER2 compared with non-transfected MSM-treated MCF-7 cells (Fig. 4C). Expression levels of STAT5b and HER2 after MSM treatment showed similar expression patterns in cell lysates, demonstrating the ability of MSM to suppress STAT5b and HER2 expression.

MSM inhibits HER2 expression in a STAT5b-dependent manner. To explore whether STAT5b is involved in HER2 expression, we used the siRNA strategy. Before MSM treatment, STAT5b in SK-BR3 cells was knocked down with a specific STAT5b siRNA. Interestingly, the results showed a similar pattern for STAT5b and HER2, with the knockdown of STAT5b leading to decreased HER2 protein expression. After MSM treatment, the HER2 expression was less in cells targeted with siSTAT5b than in cells treated with non-targeting siRNA (Fig. 5A). The relative expression of proteins, with respect to actin, gave a clear view of the effect of regulating STAT5b-related HER2 expression with MSM (Fig. 5B). From there results, we concluded that STAT5b plays an essential role in HER2 activation.

\section{Discussion}

Overexpression of HER2 is reported in $\sim 25 \%$ of breast cancer cases and is associated with an unfavorable prognosis (31). When a breast cell expresses abnormally high levels of HER2, it drives breast cancer growth and metastasis. Increased receptor activation and signaling contributes to a more aggressive tumor biology with prominent metastasis to the visceral and central nervous systems, recurrence, and mortality $(32,33)$. Hence, immense research has been carried out worldwide to inhibit HER2 and the HER2 subtype of breast cancer. Multiple approaches have been developed and examined to suppress ligand binding to the receptor or inhibit receptor activation and thereby block the HER2 signaling cascade $(16,17,34,35)$. Recently, we reported that the natural compound MSM suppresses HER2 (29). The result draws attention to solve the various problems caused by the overexpression of Her2.

In the present study, we examined the anticancer effects of MSM on the HER2 subtype of breast cancer. The proliferation inhibition analysis showed the suitable concentration of MSM was $300 \mathrm{mM}$, and this was used for further analysis (Fig. 1). The role of STAT as a transcription factor for regulating HER2 expression was demonstrated in previous studies. Both STAT3 and STAT5b have some role in modulating the expression of HER2 $(28,29,36)$. The ability of MSM to modulate the expression, as well as phosphorylation, of STAT5b was studied using western blotting. The results were consistent with our hypothesis that MSM inhibits HER2 gene expression through STAT5b. The findings were also similar in a luminal A subtype of breast cancer with a basal level expression of HER2 (5), demonstrated the significance of using MSM in multiple breast cancer subtypes (Fig. 2A and B).

The STAT5b signaling is dependent on its ability to translocate to the nucleus and bind to the nuclear response element (19). The western blot analysis of nuclear extracts showed a decline in the phosphorylated STAT5 level, indicating that the nuclear translocation was also affected by MSM treatment (Fig. 3A). Moreover, transcriptional level expression studies of HER 2 also showed a prominent inhibition by MSM treatment (Fig. 2C and D). We hypothesized that STAT5b-transcription factor (STAT5b-TF) binds to the promoter region of the HER2 (ERBB2) gene and inhibits the transcription of HER2. In support of our hypothesis, EMSA data showed inhibition in the DNA binding activities of STAT5b-TF after MSM treatment (Fig. 3B). Sequence analysis showed a GAS element in the Her2 gene promoter. The DNA binding was re-confirmed by ChIP analysis (Fig. 3D). Similar to the EMSA data, the MSM treatment drastically inhibited the STAT5b-TF/DNA binding.

The promoter regulatory functions of STAT5b-TF were studied with a luciferase assay. The result confirmed that MSM decreased the STAT5b-TF/DNA binding together with the promoter activities (Fig. 4A). To confirm our hypothesis, we used luminal A type MCF-7 cells, which do not overexpress HER2 (37). The MCF-7 cells were induced for STAT5b overexpression and analyzed for HER2 expression levels (Fig. 4B and C). Consistent with our hypothesis, STAT5b overexpression led to the overexpression of HER 2 and the results were reversed with MSM treatment. In addition, the STAT5b knockdown studies confirmed the role of STAT5b in MSMmediated downregulation of HER2 (Fig. 5A and B).

In conclusion, we confirmed that MSM has the ability to regulate the expression, as well as phosphorylation, of STAT5b. This, in turn, inhibits the STAT5b-TF functions and the expression of HER2 in this subtype of breast cancer. Hence, MSM should be evaluated as a trial drug for targeting HER2-positive breast cancers.

\section{Acknowledgements}

This study was supported by the Basic Science Research Program through the National Research Foundation of Korea (NRF); Ministry of Education (2013R1A1A2057942).

\section{References}

1. Jemal A, Bray F, Center MM, Ferlay J, Ward E and Forman D: Global cancer statistics. CA Cancer J Clin 61: 69-90, 2011.

2. Hulka BS and Moorman PG: Breast cancer: Hormones and other risk factors. Maturitas 38: 103-113, discussion 113-116, 2001. 
3. Baan R, Straif K, Grosse Y, Secretan B, El Ghissassi F, Bouvard V, Altieri A and Cogliano V; WHO International Agency for Research on Cancer Monograph Working Group: Carcinogenicity of alcoholic beverages. Lancet Oncol 8: 292-293, 2007.

4. Key J, Hodgson S, Omar RZ, Jensen TK, Thompson SG, Boobis AR, Davies DS and Elliott P: Meta-analysis of studies of alcohol and breast cancer with consideration of the methodological issues. Cancer Causes Control 17: 759-770, 2006.

5. Bertucci F, Finetti P and Birnbaum D: Basal breast cancer: A complex and deadly molecular subtype. Curr Mol Med 12: 96-110, 2012

6. Lumachi F, Brunello A, Maruzzo M, Basso U and Basso SM: Treatment of estrogen receptor-positive breast cancer. Curr Med Chem 20: 596-604, 2013.

7. Arvold ND, Taghian AG, Niemierko A, Abi Raad RF, Sreedhara M, Nguyen PL, Bellon JR, Wong JS, Smith BL and Harris JR: Age, breast cancer subtype approximation, and local recurrence after breast-conserving therapy. J Clin Oncol 29: 3885-3891, 2011

8. Carey LA, Perou CM, Livasy CA, Dressler LG, Cowan D, Conway K, Karaca G, Troester MA, Tse CK, Edmiston S, et al Race, breast cancer subtypes, and survival in the Carolina Breast Cancer Study. JAMA 295: 2492-2502, 2006

9. Potemski P, Kusinska R, Watala C, Pluciennik E, Bednarek AK and Kordek R: Prognostic relevance of basal cytokeratin expression in operable breast cancer. Oncology 69: 478-485, 2005.

10. Dent R, Trudeau M, Pritchard KI, Hanna WM, Kahn HK, Sawka CA, Lickley LA, Rawlinson E, Sun P and Narod SA: Triple-negative breast cancer: Clinical features and patterns of recurrence. Clin Cancer Res 13: 4429-4434, 2007.

11. Lund MJ, Butler EN, Hair BY, Ward KC, Andrews JH, OpreaIlies G, Bayakly AR, O'Regan RM, Vertino PM and Eley JW: Age/race differences in HER 2 testing and in incidence rates for breast cancer triple subtypes: A population-based study and first report. Cancer 116: 2549-2559, 2010.

12. Mayer IA: Treatment of HER2-positive metastatic breast cancer following initial progression. Clin Breast Cancer 9 (Suppl 2): S50-S57, 2009.

13. Yarden Y and Sliwkowski MX: Untangling the ErbB signalling network. Nat Rev Mol Cell Biol 2: 127-137, 2001.

14. Slamon DJ, Clark GM, Wong SG, Levin WJ, Ullrich A and McGuire WL: Human breast cancer: Correlation of relapse and survival with amplification of the HER-2/neu oncogene. Science 235: 177-182, 1987.

15. Slamon DJ, Godolphin W, Jones LA, Holt JA, Wong SG, Keith DE, Levin WJ, Stuart SG, Udove J, Ullrich A, et al: Studies of the HER-2/neu proto-oncogene in human breast and ovarian cancer. Science 244: 707-712, 1989.

16. Murphy CG and Fornier M: HER2-positive breast cancer: Beyond trastuzumab. Oncology (Williston Park) 24: 410-415, 2010.

17. Zhou Z and Hick DG: HER2 Amplification or Overexpression in Upper GI Tract and Breast Cancer with Clinical Diagnosis and Treatment. Siregar Y (ed). INTECH Open Access Publisher, 2013.

18. Xing X, Wang SC, Xia W, Zou Y, Shao R, Kwong KY, Yu Z, Zhang S, Miller S, Huang L, et al: The Ets protein PEA3 suppresses HER-2/neu overexpression and inhibits tumorigenesis. Nat Med 6: 189-195, 2000.

19. Furth PA: STAT signaling in different breast cancer sub-types. Mol Cell Endocrinol 382: 612-615, 2014.

20. Bowman T, Garcia R, Turkson J and Jove R: STATs in oncogenesis. Oncogene 19: 2474-2488, 2000.

21. Duru N, Fan M, Candas D, Menaa C, Liu HC, Nantajit D, Wen Y, Xiao K, Eldridge A, Chromy BA, et al: HER2-associated radioresistance of breast cancer stem cells isolated from HER2-negative breast cancer cells. Clin Cancer Res 18: 6634-6647, 2012.
22. William EJ: MSM reviewed. J Equine Vet Sci 7: 1987.

23. Silva Ferreira AC, Rodrigues P, Hogg T and Guedes De Pinho P Influence of some technological parameters on the formation of dimethyl sulfide, 2-mercaptoethanol, methionol, and dimethyl sulfone in port wines. J Agric Food Chem 51: 727-732, 2003.

24. Rose SE, Chalk JB, Galloway GJ and Doddrell DM: Detection of dimethyl sulfone in the human brain by in vivo proton magnetic resonance spectroscopy. Magn Reson Imaging 18: 95-98, 2000.

25. Caron JM, Bannon M, Rosshirt L, Luis J, Monteagudo L, Caron JM and Sternstein GM: Methyl sulfone induces loss of metastatic properties and reemergence of normal phenotypes in a metastatic cloudman S-91 (M3) murine melanoma cell line. PLoS One 5: e11788, 2010.

26. Barrager E, Veltmann JR Jr, Schauss AG and Schiller RN: A multicentered, open-label trial on the safety and efficacy of methylsulfonylmethane in the treatment of seasonal allergic rhinitis. J Altern Complement Med 8: 167-173, 2002.

27. Kim LS, Axelrod LJ, Howard P, Buratovich N and Waters RF: Efficacy of methylsulfonylmethane (MSM) in osteoarthritis pain of the knee: A pilot clinical trial. Osteoarthritis Cartilage 14: 286-294, 2006

28. Joung YH, Lim EJ, Darvin P, Chung SC, Jang JW, Do Park K, Lee HK, Kim HS, Park T and Yang YM: MSM enhances GH signaling via the Jak2/STAT5b pathway in osteoblast-like cells and osteoblast differentiation through the activation of STAT5b in MSCs. PLoS One 7: e47477, 2012.

29. Lim EJ, Hong DY, Park JH, Joung YH, Darvin P, Kim SY, Na YM, Hwang TS, Ye SK, Moon ES, et al: Methylsulfonylmethane suppresses breast cancer growth by down-regulating STAT3 and STAT5b pathways. PLoS One 7: e33361, 2012.

30. Kim JH, Shin HJ, Ha HL, Park YH, Kwon TH, Jung MR, Moon HB, Cho ES, Son HY and Yu DY: Methylsulfonylmethane suppresses hepatic tumor development through activation of apoptosis. World J Hepatol 6: 98-106, 2014.

31. Ross JS: Update on HER2 testing for breast and upper gastrointestinal tract cancers. Biomarkers Med 5: 307-318, 2011.

32. Winstanley J, Cooke T, Murray GD, Platt-Higgins A, George WD, Holt S, Myskov M, Spedding A, Barraclough BR and Rudland PS: The long term prognostic significance of c-erbB-2 in primary breast cancer. Br J Cancer 63: 447-450, 1991

33. Hicks DG, Yoder BJ, Short S, Tarr S, Prescott N, Crowe JP, Dawson AE, Budd GT, Sizemore S, Cicek M, et al: Loss of breast cancer metastasis suppressor 1 protein expression predicts reduced disease-free survival in subsets of breast cancer patients. Clin Cancer Res 12: 6702-6708, 2006.

34. Gajria D and Chandarlapaty S: HER2-amplified breast cancer: Mechanisms of trastuzumab resistance and novel targeted therapies. Expert Rev Anticancer Ther 11: 263-275, 2011.

35. Emde A, Köstler WJ and Yarden Y; Association of Radiotherapy and Oncology of the Mediterranean arEa (AROME): Therapeutic strategies and mechanisms of tumorigenesis of HER2-overexpressing breast cancer. Crit Rev Oncol Hematol 84 (Suppl 1): e49-e57, 2012.

36. Chung SS, Giehl N, Wu Y and Vadgama JV: STAT3 activation in HER2-overexpressing breast cancer promotes epithelialmesenchymal transition and cancer stem cell traits. Int J Oncol 44: 403-411, 2014.

37. Subik K, Lee JF, Baxter L, Strzepek T, Costello D, Crowley P, Xing L, Hung MC, Bonfiglio T, Hicks DG, et al: The expression patterns of ER, PR, HER2, CK5/6, EGFR, Ki-67 and AR by immunohistochemical analysis in breast cancer cell lines. Breast Cancer (Auckl) 4: 35-41, 2010.

38. Joung YH, Lim EJ, Lee MY, Park JH, Ye SK, Park EU, Kim SY, Zhang Z, Lee KJ, Park DK, et al: Hypoxia activates the cyclin D1 promoter via the Jak2/STAT5b pathway in breast cancer cells. Exp Mol Med 37: 353-364, 2005. 